\title{
Double ligation-assisted endoscopic submucosal resection for rectal neuroendocrine tumors
}
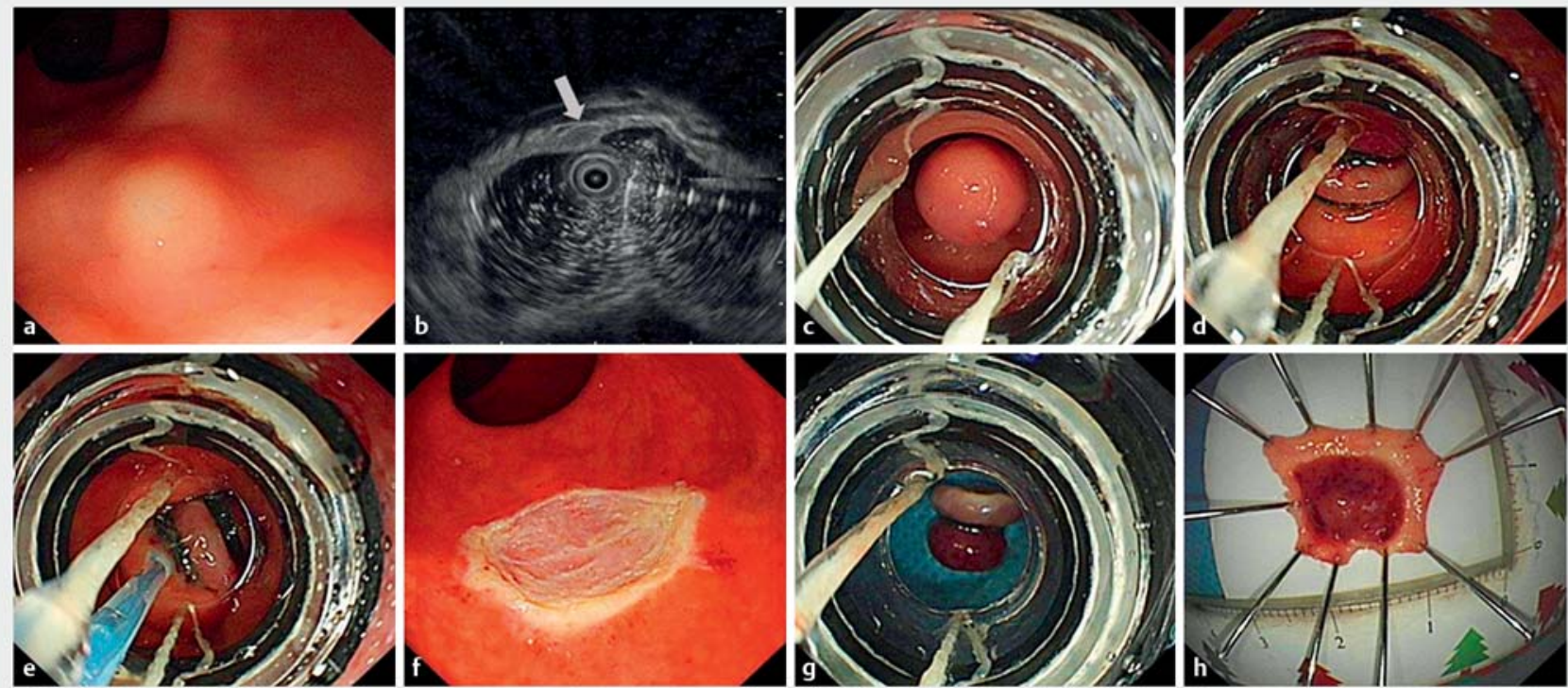

- Fig. 1 Steps in the double ligation-assisted endoscopic submucosal resection procedure. a, b Endoscopy and endoscopic ultrasound showed a hypoechoic lesion originating from the submucosa layer (indicated by the arrow). $\mathbf{c}$ The first band was placed. $\mathbf{d}$ The second band was deployed. e Completion of the resection using a snare. $\mathbf{f}$ Postoperative mucosal defect. g, h Postoperative specimens.

Rectal neuroendocrine tumors (NETs) are rare neoplasms with a relatively good prognosis. Currently, the first choice of treatment is endoscopic resection if the rectal NET is $\leq 10 \mathrm{~mm}$ because of the low risk of metastasis [1,2]. Although conventional endoscopic mucosal resection (EMR) was considered an option for rectal NETs, it is difficult to achieve deep resection margins because most rectal NETs invade the submucosal layer. Therefore, modified EMR, including EMR with ligation (EMR-L) and EMR after circumferential incision, is widely performed because it has a low technical burden and short procedure time compared with endoscopic submucosal dissection [3]. EMR-L was recently introduced for securing a deep resection margin easily and safely; however, according to previous reports, the $\mathrm{R} 0$ resection rate varies from $86.2 \%$ to $92.5 \%[4,5]$.

We present a novel variant EMR technique, double ligation-assisted endo-

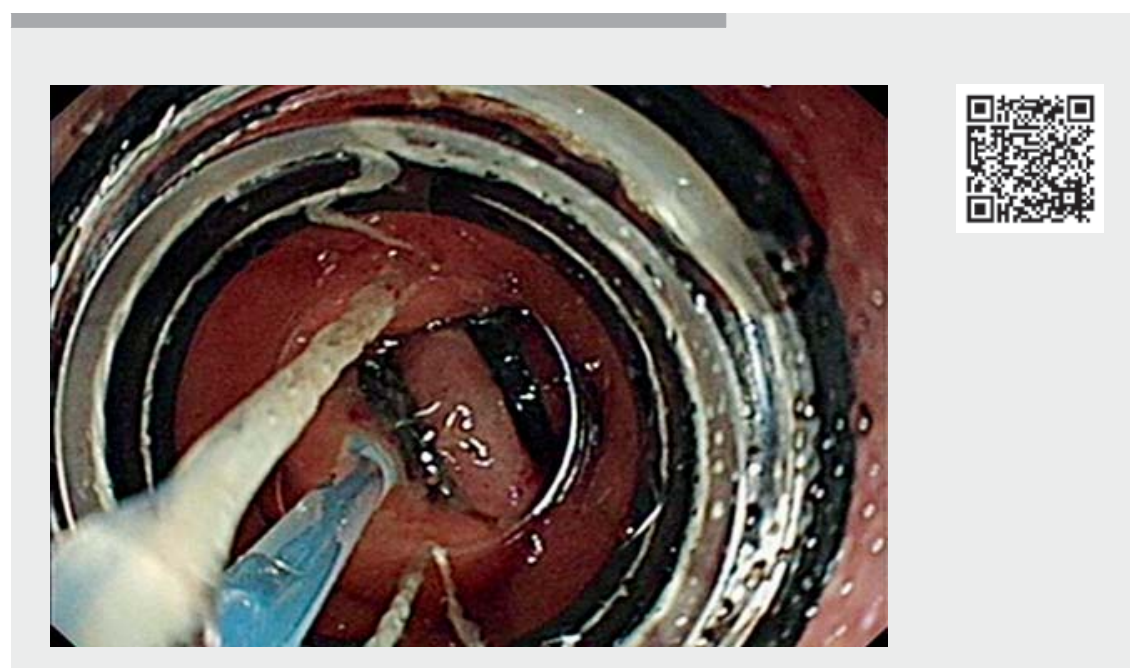

Video 1 The steps of the double ligation-assisted endoscopic submucosal resection procedure.

scopic submucosal resection (ESMR-DL), for achieving a deeper vertical resection margin compared with EMR-L. The ESMR-
DL procedure was successfully carried out as follows ( Fig.1, Video 1). First, endoscopic ultrasound was performed to 
assess the exact size and depth of invasion before treatment. After a standard endoscopic variceal ligation device had been attached to the scope, the lesion was suctioned into the ligating device without prior submucosal injection. Next, an elastic band was placed to increase luminal protuberance, followed by a second band that was deployed after endoscopic suctioning of the tumor into the cap. Then, a snare was looped around the lesion and electrocautery was applied for resection. The mucosal defect was then left open. The result showed both endoscopic en bloc resection and histologic complete resection of the lesion. Although ESMR-DL may be the preferable method for endoscopic resection of rectal NETs, further studies with more cases are needed to validate the advantage of this technique.

Endoscopy_UCTN_Code_CCL_1AD_2AI

\section{Competing interests}

The authors declare that they have no conflict of interest.

The authors

Wei Liu, Xiang-Lei Yuan, Bing Hu $\bullet$

Department of Gastroenterology, West China Hospital, Sichuan University, Chengdu, China
Corresponding author

\section{Bing Hu, MD}

Department of Gastroenterology, West China Hospital, Sichuan University, 37 Guo Xue Alley, Wuhou District, Chengdu City, Sichuan Province, China

hubingnj@163.com

\section{References}

[1] Choi CW, Park SB, Kang DH et al. The clinical outcomes and risk factors associated with incomplete endoscopic resection of rectal carcinoid tumor. Surg Endosc 2017; 31: 5006-5011

[2] Yamashina T, Tumura T, Maruo T et al. Underwater endoscopic mucosal resection: a new endoscopic method for resection of rectal neuroendocrine tumor grade 1 (carcinoid) $\leq 10 \mathrm{~mm}$ in diameter. Endosc Int Open 2018; 6: E111-E114

[3] Lim HK, Lee S], Baek DH et al. Resectability of rectal neuroendocrine tumors using endoscopic mucosal resection with a ligation band device and endoscopic submucosal dissection. Gastroenterol Res Pract 2019; 2019: 1-10

[4] Inada Y, Yoshida N, Fukumoto K et al. Risk of lymph node metastasis after endoscopic treatment for rectal NETs $10 \mathrm{~mm}$ or less. Int J Colorectal Dis 2021. doi:10.1007/s00384020-03826-1

[5] Lee J, Park YE, Choi JH et al. Comparison between cap-assisted and ligation-assisted endoscopic mucosal resection for rectal neuroendocrine tumors. Ann Gastroenterol 2020; 33: 385-390
Bibliography

Endoscopy 2022; 54: E106-E107

DOI 10.1055/a-1398-5378

ISSN 0013-726X

published online 30.3.2021

(c) 2021. Thieme. All rights reserved.

Georg Thieme Verlag KG, Rüdigerstraße 14, 70469 Stuttgart, Germany

ENDOSCOPY E-VIDEOS

https://eref.thieme.de/e-videos

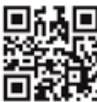

Endoscopy E-Videos is an open access online section, reporting on interesting cases and new techniques in gastroenterological endoscopy. All papers include a high quality video and all contributions are freely accessible online. Processing charges apply (currently EUR 375), discounts and wavers acc. to HINARI are available.

This section has its own submission website at https://mc.manuscriptcentral.com/e-videos 